A.C. Webster BSc MB ChB FFARCS FRCP,

P.K. Morley-Forster MD FRCP, S. Dain MD FRCP,

S. Ganapathy MD FRCP, R. Ruby MD FRCS, A. Au meds III, Mary Jo Cook RN

\title{
Anaesthesia for adenotonsillectomy: a comparison between tracheal intubation and the armoured laryngeal mask airway
}

A prototype armoured laryngeal mask airway (LMA) was compared with tracheal intubation (ETT) for anaesthesia for adenotonsillectomy. Fifty-five children were randomised into the LMA group and 54 into the ETT group. During insertion of the LMA, peripheral oxyhaemoglobin desaturation $\left(\mathrm{SpO}_{2}\right)$ $<94 \%$ occurred in ten patients $(18.2 \%)$ and in seven patients (13\%) during tracheal intubation (NS). After opening the BoyleDavis gag, airway obstruction occurred in ten patients (18.2\%) in the LMA group and in three patients (6\%) in the ETT group $(P=0.07)$. In five patients (9\%) the LMA was abandoned in favour of tracheal intubation. In all others (91\%), when the need for adequate depth of anaesthesia was realized, a satisfactory airway was achieved more rapidly than with tracheal intubation $(P<0.001)$, and maintained throughout surgery. Manually assisted ventilation was required in all patients in the ETT group, mean duration $373 \pm 385 \mathrm{sec}$, and in $26 \mathrm{pa}$ tients (52\%) in the LMA group, mean duration $134 \pm 110$ sec, $P<0.001$. Mean end-iidal $\mathrm{CO}_{2}\left(\mathrm{PETCO}_{2}\right)$ was $45.5 \pm$ $6.21 \mathrm{mmHg}$ in the ETT group and $46.6 \pm 6.09$ in the LMA group (NS). The LMA did not limit surgical access. Heart rate, $M A P$ and blood loss in the LMA group were $110 \pm 21,74$ $\pm 9 \mathrm{mmHg}$ and $1.92 \pm 1.22 \mathrm{ml} \cdot \mathrm{kg}^{-1}$ respectively, compared with $143 \pm 13(P<0.001), 85 \pm 12 \mathrm{mmHg}(P<0.001)$ and $2.62 \pm 1.36 \mathrm{ml} \cdot \mathrm{kg}^{-1}(P<0.05)$ with tracheal intubation. Fibreoptic laryngoscopy at the end of surgery in 19 patients in the LMA group revealed no blood in the larynx. In the

\section{Key words}

ANAESTHESIA: paediatric;

EQUIPMENT: airway, laryngeal mask;

SURGERY: otolaryngological.

From the Departments of Anaesthesia and Otolaryngology, University of Western Ontario, St. Joseph's Health Centre.

Address correspondence to: Dr. A.C. Webster, Department of Anaesthesia, St. Joseph's Hospital, 268 Grosvenor Street, London, Ontario N6A 4L6.

Accepted for publication 3rd September, 1993.
LMA group postintubation stridor and laryngospasm occurred in five and three patients respectively, compared with 14 (P $<0.05$ ) and six patients respectively $(N S)$ with tracheal intubation. $\mathrm{SpO} \mathrm{O}_{2}$ on admission to the $P A C U$ in the LMA group was $95.9 \pm 2.21$, and $93.5 \pm 4.53(P<0.05)$ after tracheal intubation. Our study demonstrated that the LMA is a safe alternative to tracheal intubation for adenotonsillectomy. Control of airway reflexes by ensuring sufficient depth of anaesthesia is essential for successful use of the LMA in children.

Un prototype de masque larngyé armé (ML) est comparé à lintubation trachéale (TE) pendant l'anesthésie pour adénoamygdalectomie. Cinquante-cing enfants sont assignés au hasard au groupe $M L$ et 54 au groupe TE. Pendant linsertion du $M L$, une désaturation périphérique inférieure à $94 \%$ survient chez dix patients $(18,2 \%)$ et pendant lintubation trachéale chez sept patients (13\%) (NS). Après la mise en place de l'ouvrebouche de Boyle-Davis, l'obstruction des voies aériennes supérieures survient chez dix patients $(18,2 \%)$ dans la groupe $M L$ et trois patients dans le groupe TE $(P=0.07)$. Chez cinq patients (9\%), on abandonne le $M L$ en faveur de lintubation trachéale. Chez tous les autres (91\%), après l'atteinte d'un niveau d'anesthésie adéquat, un airway satisfaisant est réalisé plus rapidement quavec lintubation trachéale $(P<0,001)$ et maintenu pendant la chirurgie. Une ventilation assistée manuellement devient nécessaire pour tous les patients du groupe TE, avec une durée moyenne de $373 \pm 385 \mathrm{sec}$, et chez 26 patients (52\%) du groupe $M L$, avec une durée moyenne de $134 \pm 110$ sec $(P<0,001)$. Le $\mathrm{CO}_{2}$ télé-expiratoire $\left(\mathrm{PETCO}_{2}\right)$ est de 45,5 $\pm 6,21 \mathrm{mmHg}$ dans le groupe TE et de 46,6 $\pm 6,09 \mathrm{mmHg}$ dans le groupe MLA (NS). Le MLA ne limite pas l'accès chirurgical. La fréquence cardiaque, la PAM et la perte sanguine est de $110 \pm 21,74 \pm 9 \mathrm{mmHg}$ et $1,92 \pm 1,22 \mathrm{ml} \cdot \mathrm{kg}^{-1}$ respectivement pour le groupe $M L$, comparativement à $143 \pm$ $13(P<0,001), 85 \pm 12 \mathrm{mmHg}(P<0,001)$ et $2,62 \pm 1,36$ $\mathrm{ml} \cdot \mathrm{kg}^{-1}(P<0,05)$ pour le groupe TE. Chez 19 patients du groupe $M L$, la fibroscopie à la fin de la chirurgie n'a pas révélé la présence de sang dans le larynx. Dans le groupe $M L$ 
après lintubation, un stridor et un laryngospasme sont apparus chez cinq et trois patients respectivement, comparativement à 14 $(P<0,05)$ et six patients respectivement (NS) dans le groupe TE. Notre étude montre que le $M L$ est une alternative sécuritaire à l'intubation trachéale pour l'adéno-amygdalectomie. Pour utiliser avec succès la LM, il est essentiel de contróler les réflexes des voies aériennes par une anesthésie suffisamment profonde.

Control and protection of the airway are fundamental considerations in anaesthesia. During the past four decades, tracheal intubation has become the standard for anaesthesia for adenotonsillectomy (T\&A), ${ }^{1-4}$ which remains one of the commonest surgical procedures in children. Competition for the airway between surgeon and anaesthetist is avoided by placing the tracheal tube beneath the grooved tongue blade of the Boyle-Davis (B-D) gag. Neither tracheal intubation nor the B-D gag is innocuous.

Frequent and occasionally serious complications of tracheal intubation (ETT) include trauma, cardiovascular stimulation, endobronchial or oesophageal intubation, coughing, bronchospasm, laryngospasm and laryngeal oedema with airway obstruction after extubation. The tracheal tube may be advanced, compressed, kinked and partially obstructed by the tongue blade of the B-D gag, or prematurely extubated when it is removed. ${ }^{5,6}$ Succinylcholine, if used to facilitate tracheal intubation, may cause sinus bradycardia and arrhythmias, hyperkalaemia and myoglobinaemia, muscle pain, malignant hyperthermia and masseter spasm confusing the diagnosis of malignant hyperthermia, and prolonged neuromuscular blockade in patients with pseudocholinesterase deficiency.

The laryngeal mask airway (LMA) is a new airway adjunct introduced in the U.K. in $1988^{7-9}$ and in Canada in $1990 .{ }^{10}$ It is inserted blindly into the pharynx where it forms a low pressure seal around the laryngeal inlet. Neither instrumentation nor neuromuscular blockade is needed, pharyngeal trauma is minimized and laryngeal trauma avoided, and there is no risk of endobronchial or oesophageal intubation. Prototype LMA's with longer, smaller diameter flexometallic tubes for ENT and dental anaesthesia were described in $1990,{ }^{11}$ and for adenotonsillectomy in $1993 .^{12}$

The objectives of this study were to assess the suitability of the armoured LMA for anaesthesia for T\&A, and to compare the incidence of complications with its use with those of tracheal intubation.

\section{Methods}

With parental consent and approval of the institutional and University Ethics Committees, 109 ASA 1 and 2 children scheduled for T\&A or adenoidectomy with or without bilateral myringotomy and ventilation tubes (BMT) were randomized into two groups; 55 in Group 1 (LMA), and 54 in Group 2 (ETT). The sample size was calculated using an $\alpha$ level of $5 \%$ and power of $80 \%$, anticipating that extubation complications would occur in approximately $25 \%$ of the ETT group, ${ }^{13}$ and in approximately $5 \%$ of the LMA group. ${ }^{14}$ Exclusion criteria included congenital defects involving the upper airway, active respiratory tract infection as indicated by rhonchi and/or pyrexia, and recent intake of food or fluids, within the previous six hours and four hours respectively.

Children were admitted to the Children's Ambulatory Care Unit and returned there from the post-anaesthesia care unit (PACU). No child received premedication. Those living within a short distance of the hospital, about $70 \%$, were discharged home after six hours of observation. Otherwise, children were admitted overnight, and sent home the following day.

Monitors included: suprasternal stethoscope, ECG, automatic sphygmomanometer (Dinamap), axillary temperature probe, and Nellcor N1000/N2500 pulse oximeter, capnometer and agent analyzer. A computerized data acquisition system was used. The outputs of the Nellcor and Dinemap monitors were interfaced with a laptop computer, linking them through customized software which includes a word processing programme, to record demographic data and details of anaesthesia at the time of surgery. ${ }^{15}$ Function keys were designated as event markers to identify events during anaesthesia and measure time intervals accurately. Peripheral oxyhaemoglobin saturation $\left(\mathrm{SpO}_{2}\right)$, end-tidal $\mathrm{CO}_{2}\left(\mathrm{PeTCO}_{2}\right)$, heart rate, and systolic, mean and diastolic blood pressure cycling at one-minute intervals, were recorded every ten seconds from induction of anaesthesia to the patient's leaving the operating room. Data were recorded on the computer's hard disc, and transferred to Microsoft Excel for Windows spreadsheet format for subsequent analysis.

Anaesthesia was administered by four anaesthetists, all experienced at tracheal intubation in children, but initially relatively unfamiliar with the LMA for T\&A. Using mask inhalation analgesia with nitrous oxide/ oxygen $40 \%$ and an inspired halothane concentration of $0.2-0.4 \%$, a secure intravenous infusion was established and lactated Ringer's solution administered. After preoxygenation, in both groups, anaesthesia was induced with propofol 2.5-4.0 $\mathrm{mg} \cdot \mathrm{kg}^{-1}$, followed by succinylcholine $1.5 \mathrm{mg} \cdot \mathrm{kg}^{-1}$ iv in the ETT group. Atropine $0.01-0.02 \mathrm{mg} \cdot \mathrm{kg}^{-1}$ was administered $i v$ before succinylcholine to all patients in the ETT group and to 12 patients in the LMA group, at the discretion of the anaesthetist.

In the LMA group patients, after assessing jaw relaxation, a prototype \#2 armoured LMA (Figure 1) was 


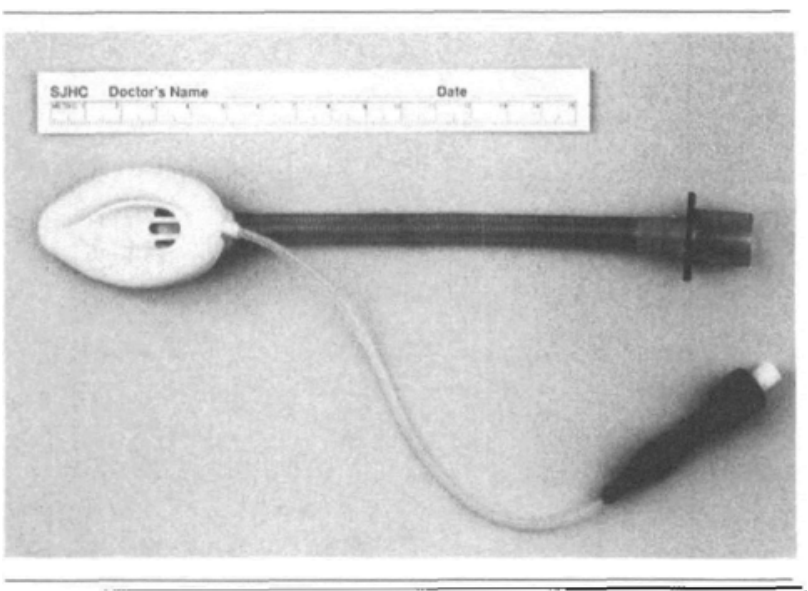

FIGURE 1 Size 2 "Intavent" armoured laryngeal mask airway Vitaid, Ltd., 240 Melrose Avenue, Toronto, Ontario, M5M IZl.

inserted, the cuff inflated with $10 \mathrm{ml}$ air, connected to a coaxial breathing circuit and air entry confirmed by auscultation and capnography. In the ETT group, after allowing time for full neuromuscular blockade, the appropriate size uncuffed RAE tracheal tube was inserted and similarly connected. Correct placement and a small leak with positive pressure ventilation were confirmed by auscultation. Ventilation was manually assisted until return of adequate spontaneous breathing as judged by breath sounds and capnography, and anaesthesia was maintained with nitrous oxide/oxygen $40 \%$ and halothane equilibrated to end-tidal concentration of between $1.0 \%$ and $1.5 \%$.

The surgical field was exposed with the LMA or tracheal tube placed beneath the grooved tongue blade of the B-D gag. Insertion and placement of the tongue blade over the LMA tube was facilitated with water soluble lubricant applied to the sides of the groove. The gag was opened gradually, while carefully monitoring breath sounds and the capnograph. Adenoidectomy was performed by curettage, and tonsillectomy by dissection. Haemostasis was obtained by ligature, electrocautery, and application of tonsil plugs soaked in a mixture of $0.5 \%$ neosynephrine and bismuth subgallate. Blood loss was measured in a graduated burette.

After inspection of the pharynx, all children were turned into the lateral position before extubation; in two ETT group children $<10 \mathrm{~kg}$, extubation was performed awake. In all others, extubation was performed while breathing spontaneously at the depth of anaesthesia used during surgery, or in the ETT group, increased before extubation to suppress cough reflex in those patients in whom it might be activated by turning. Meperidine 1.0 $\mathrm{mg} \cdot \mathrm{kg}^{-1}$ im was then given. Oxygen (100\%) was administered by face mask until return of purposeful activity. When it was certain that the airway was unob- structed and ventilation adequate, the patient was returned to the PACU.

To confirm that the LMA was correctly placed, and to determine whether there was blood in the larynx, in 19 patients fibreoptic laryngoscopy was performed at the conclusion of surgery. Adverse events were recorded in sequence using the function keys; cough, difficulty and oxyhaemoglobin desaturation when inserting the airway, airway obstruction, apnoea and oxyhaemoglobin desaturation after opening the B-D gag, cough, stridor, laryngospasm and oxyhaemoglobin desaturation after extubation. Stridor was defined as a high-pitched laryngeal sound with inspiratory soft tissue and lower rib retraction, but no oxyhaemoglobin desaturation with assisted bag/ mask ventilation with $100 \%$ oxygen. Laryngospasm was defined as the failure of bag and mask ventilation with $100 \%$ oxygen to prevent oxyhaemoglobin desaturation. Duration of assisted ventilation was measured by analysis of the $\mathrm{PETCO}_{2}$ record of each patient (Figure 2).

Oxygen by face mask was administered to all children on admission to the PACU and until return of consciousness. In 26 patients in the LMA group and 33 in the ETT group, $\mathrm{SpO}_{2}$ while breathing air was measured immediately on admission to the PACU. Oxygen was then administered by face mask until the child was fully conscious.

The demographic, respiratory and haemodynamic data and the incidence of complications were compared by Student's $t$ test, by Chi-square test or the Fisher exact test, and the Kruskall-Wallis test where appropriate. A value of $P<0.05$ was considered significant.

\section{Results}

Ages, weights, and surgical procedures were similar in each group (Table I). Fifteen patients, six in Group 1 and nine in Group 2, had recent upper respiratory infections (URI), either "colds" during the previous two weeks or runny noses at the time of surgery. On preanaesthetic assessment, all were afebrile, chest auscultation was negative, and the infection was judged to be inactive. Airway management and the incidence of complications are summarized in Table II. For the purposes of the study, desaturation was defined as $\mathrm{SpO}_{2} \leq 94 \%$. Respiratory data are summarized in Table III and haemodynamic data for patients having T\&A, 38 in the LMA group and 41 in the ETT group are summarized in Table IV.

Early in the study, there was difficulty on inserting the LMA in ten cases (18.2\%), compared with none during tracheal intubation $(P<0.001)$. Oxyhaemoglobin desaturation occurred in ten patients (18.2\%) during insertion of the LMA, compared with seven patients during tracheal intubation (13\%) (NS). In four patients, the LMA 


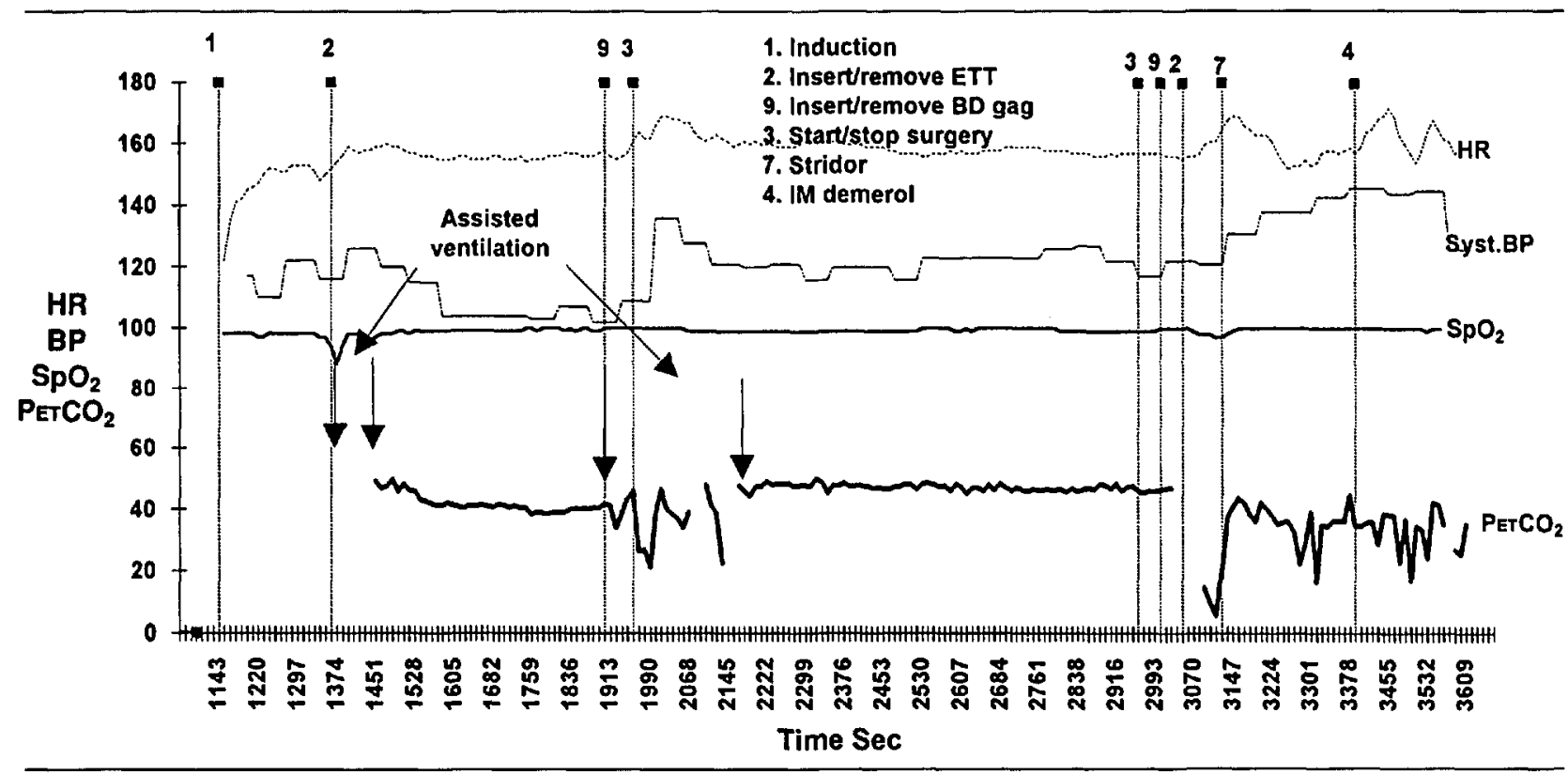

FIGURE 2 Computer-generated anaesthetic record.

TABLE I Demographic data

\begin{tabular}{lcc}
\hline & $\begin{array}{l}\text { Group I. LMA } \\
n=55\end{array}$ & $\begin{array}{l}\text { Group 2. ETT } \\
n=54\end{array}$ \\
\hline Males & 32 & 29 \\
Age (yr) & $4.99 \pm 1.69$ & $4.38 \pm 1.85$ \\
Weight (kg) & $19.9 \pm 5.07$ & $18.35 \pm 4.9$ \\
T\&A & 25 & 30 \\
BMT, T\&A & 13 & 11 \\
BMT, Adenoidectomy & 10 & 11 \\
Adenoidectomy & 2 & 2 \\
Recovering URI & 6 & 9 \\
Converted to E/T & 5 & \\
\hline
\end{tabular}

There were no significant differences between the two groups.

was reinserted because of a leak on positive pressure ventilation. In one of these, a child with extremely large tonsils, the attempt was abandoned and tracheal intubation was performed. In another case with a recent URI, bronchospasm with reduction of $\mathrm{SpO}_{2}$ to $80 \%$ occurred after insertion of the LMA. Aspiration was considered to be a possible cause, and tracheal intubation to be prudent. After tracheal intubation, bronchospasm was more severe with $\mathrm{SpO}_{2}$ reduced to $63 \%$.

The LMA was stabilized beneath the tongue blade of the B-D gag, and did not limit surgical access in any way. After opening the B-D gag, cough and apnoea occurred in three patients (5\%) in the LMA group. In the ETT group, cough occurred in one patient and apnoea in five $(9 \%)$ (NS). In ten patients $(18.2 \%)$ in the LMA group, the airway became obstructed when the B-D gag was opened, with transient oxyhaemoglobin desaturation in five of these cases. Three of these were converted to tracheal intubation. In all others an adequate airway was obtained after temporarily releasing the gag, increasing the depth of anaesthesia, and gentle positive pressure ventilation until satisfactory spontaneous ventilation was established, as indicated by breath sounds and capnography. In one patient in the LMA group, there was partial airway obstruction throughout surgery, indicated by mild stridor and inspiratory indrawing, without oxyhaemoglobin desaturation of hypercapnia $>55 \mathrm{mmHg}$. All of the five cases in the LMA group converted to tracheal intubation occurred in the first 15 of the study.

The dose of propofol used at the beginning of the study, $2.5 \mathrm{mg} \cdot \mathrm{kg}^{-1}$, did not consistently provide adequate jaw relaxation and suppression of cough reflex. With practice and the improved conditions obtained when the dose of propofol was increased in each group to 3.5-4.0 $\mathrm{mg} \cdot \mathrm{kg}^{-1}$, a satisfactory airway was obtained using the LMA more rapidly than with tracheal intubation. The mean duration from $i v$ induction to insertion of the LMA, was $64.0 \pm 45.3 \mathrm{sec}$, and for tracheal intubation, 97.0 $\pm 45.4 \mathrm{sec}(P<0.001)$.

In the ETT group, when the B-D gag was opened the airway became obstructed in three patients $(6 \%)$. In two, the tracheal tube was kinked at the angle at which it emerged from the mouth. In one patient, there was mild partial airway obstruction indicated by inspiratory indrawing, without oxyhaemoglobin desaturation, throughout surgery. The obstruction was not relieved by repositioning the gag. 
TABLE Il Airway management: LMA and ETT incidence (and percent incidence) of complications

\begin{tabular}{lccc}
\hline & $\begin{array}{l}\text { Group l. LMA } \\
n=55\end{array}$ & $\begin{array}{l}\text { Group 2. ETT } \\
n=54\end{array}$ & P value \\
\hline $\begin{array}{l}\text { Intubation } \\
\text { Difficulty }\end{array}$ & $10(18)$ & & \\
Desaturation <94\% & $10(18)$ & $7(13)$ & $0<0.001$ \\
Conversion to E/T & $5(9)$ & & 0.6 \\
Time from iv induction to insertion (sec) & $64 \pm 45.3$ & $97 \pm 45.4$ & $<0.001^{*}$ \\
& & & \\
Reaction to opening the B-D gag & $3(5)$ & $1(2)$ & 0.62 \\
Cough & $10(18)$ & $3(6)$ & 0.07 \\
Obstruction & $5(9)$ & $2(4)$ & 0.44 \\
Desaturation $<94 \%$ & $3(5)$ & $5(9)$ & 0.49 \\
Apnoea & $n$ & & \\
& $n=50$ & $3(6)$ & 0.24 \\
Reaction to removing the airway & 0 & $14(26)$ & 0.04 \\
Cough & $5(10)$ & $6(11)$ & 0.49 \\
Stridor & $3(6)$ & $6(11)$ & 0.49 \\
Laryngospasm & $3(6)$ & 47 & \\
Desaturation $<94 \%$ & 57 & $n=33$ & \\
Total adverse events & $n=26$ & $16(48)$ & 0.06 \\
SpO $\mathrm{O}_{2}$ on admission to PACU & $6(23)$ & $93.5 \pm 4.53$ & $<0.05^{*}$ \\
Desaturation $<94 \%$ & $95.9 \pm 2.21$ & \\
&
\end{tabular}

$*_{t}$ test. All other probability values by Chi-square analysis and Fisher exact test.

TABLE 111 Respiratory data

\begin{tabular}{llll}
\hline & $\begin{array}{l}\text { Group I } \\
n=50\end{array}$ & $\begin{array}{l}\text { Group 2 } \\
n=54\end{array}$ & \\
\hline Mean PETCO $_{2}$ & $45.5( \pm 6.21)$ & $46.62( \pm 6.09)$ & NS* $^{*}$ \\
$\begin{array}{l}\text { Assisted ventilation } \\
\text { (a) after intubation }\end{array}$ & $24(48 \%)$ & $54(100 \%)$ & \\
(b) maintenance of anaesthesia & $9(18 \%)$ & $31(57 \%)$ & \\
(c) throughout surgery & 0 & $5(9 \%)$ & \\
(c) total & $26(52 \%)$ & $54(100 \%)$ & $P<0.05 \dagger$ \\
& & & \\
$\begin{array}{l}\text { Mean duration of assisted ventilation } \\
\text { (a) after intubation }\end{array}$ & $83 \pm 39$ & $205 \pm 339$ & \\
(b) maintenance of anaesthesia & $167 \pm 70$ & $252 \pm 271$ & \\
(c) total sec & $134 \pm 110$ & $373 \pm 385$ & $P<0.001 \ddagger$ \\
\hline
\end{tabular}

* $t$ test. †Chi-square test. $\ddagger$ Kruskall-Wallis test.

In the ETT group, ventilation was manually assisted until return of spontaneous respiration in all patients, during maintenance of anaesthesia in 31 (57\%), and throughout surgery in five (9\%), mean duration $373 \pm 385 \mathrm{sec}$. After inserting the LMA, ventilation was assisted until return of spontaneous respiration in 26 patients $(52 \%)$, and during maintenance of anaesthesia in nine (18\%), mean duration $134 \pm 110 \mathrm{sec}, P<0.001$.

Fibreoptic laryngoscopy was performed in 19 patients
(38\%), with the LMA in place. In 18, laryngeal anatomy was normal and there was no contamination with blood. In seven patients, laryngoscopy was performed with the B-D gag open and closed. No change was seen. In two, the epiglottis was reported as visible, but not obscuring the view of the larynx. In the patient with clinical evidence of slight airway obstruction throughout, neither epiglottis nor glottis could be identified on fibreoptic laryngoscopy after completion of surgery. Partial airway obstruction 
TABLE IV Haemodynamic data: T\&A; BMT and T\&A

\begin{tabular}{|c|c|c|c|}
\hline & $\begin{array}{l}\text { Group I. LMA } \\
n=38\end{array}$ & $\begin{array}{l}\text { Group 2. ETT } \\
n=41\end{array}$ & $P$ value \\
\hline \multicolumn{4}{|l|}{ Heart rate } \\
\hline $5 \mathrm{~min}$ from $i v$ induction & $108 \pm 16$ & $140 \pm 14$ & $<0.001$ \\
\hline iv induction to end of surgery & $110 \pm 21$ & $143 \pm 13$ & $<0.001$ \\
\hline \multicolumn{4}{|l|}{ Systolic BP $\mathrm{mm} H g$} \\
\hline $5 \mathrm{~min}$ from $i v$ induction & $101 \pm 13$ & $117 \pm 18$ & $<0.001$ \\
\hline$i v$ induction to end of surgery & $103 \pm 12$ & $118 \pm 17$ & $<0.001$ \\
\hline \multicolumn{4}{|l|}{$M A P \mathrm{mmHg}$} \\
\hline$S \min$ from $\dot{w}$ induction & $72 \pm 11$ & $87 \pm 14$ & $<0.001$ \\
\hline$i v$ induction to end of surgery & $74 \pm 9$ & $86 \pm 12$ & $<0.001$ \\
\hline Blood loss $\mathrm{ml} \cdot \mathrm{kg}^{-1}$ & $1.92 \pm 1.22$ & $2.62 \pm 1.36$ & $<0.05$ \\
\hline Arrhythmia & $n=3$ & $n=3$ & \\
\hline
\end{tabular}

was relieved when the B-D gag was closed, suggesting that the laryngeal mask had been impacted in the laryngopharynx, distorting the glottis, or the epiglottis was folded over with the gag open.

After removing the LMA, stridor occurred in five patients (10\%); after removing the ETT, stridor occurred in 14 patients $(25.9 \%) P<0.05$. Laryngospasm occurred in six ETT group patients and in three in the LMA group (NS). In two patients in the LMA group, in whom an oropharyngeal airway was inserted after removing the LMA, severe laryngospasm with oxyhaemoglobin desaturation to $\mathrm{SpO}_{2}<65 \%$ occurred 4.2 and $4.8 \mathrm{~min}$ after extubation, during return of activity. This period of latency suggests that the laryngeal response was related to the presence of the oropharyngeal airway rather than removal of the LMA.

Each LMA was inspected after removal; there was no blood on the laryngeal surface of the mask beyond the cuff. In patients recovering from URI, episodes of desaturation occurred in three of six patients in the LMA group, and in five of nine patients in the ETT group (NS).

The average heart rate and mean arterial blood pressure from iv induction to the conclusion of surgery in the LMA group were $110 \pm 21$ and $74 \pm 9 \mathrm{mmHg}$, and with tracheal intubation, $143 \pm 13(P<0.001)$ and $85 \pm 12 \mathrm{mmHg}(P<0.001)$. Blood loss during T\&A in the LMA group was $1.9 \pm 1.22 \mathrm{ml} \cdot \mathrm{kg}^{-1}$, and in the ETT group, $2.62 \pm 1.36 \mathrm{ml} \cdot \mathrm{kg}^{-1}(P<0.05)$.

The time from extubation to the patient leaving the OR was the same in two groups, $344 \pm 132 \mathrm{sec}$ in the LMA group and $345 \pm 156 \mathrm{sec}$ in the ETT group. Average $\mathrm{SpO}_{2}$ on admission to the PACU in the LMA group was $95.9 \pm 2.21$ and in the ETT group, $93.5 \pm 4.53$ $(P<0.05)$.

\section{Discussion}

With high oxygen consumption and small, easily obstructed airways, children are more liable than adults to intraoperative and postoperative hypoxaemia. ${ }^{16}$ Upper airway obstruction after tracheal intubation may be transient from stridor or laryngospasm, or intractable from laryngeal oedema. In a study of postintubation croup, defined as hoarseness, stridor and critical airway obstruction, in 7875 children under $17 \mathrm{yr}$ of age, the overall incidence was $1 \%$. Of these, the highest occurrence was between one and four years of age. ${ }^{17}$ In 1984, the incidence of laryngospasm causing potentially lifethreatening airway obstruction in children one to nine years old was reported as $1.7 \% .^{18}$ Hyperactive airway reflexes associated with airway pathology and surgery contribute to difficulties in providing safe anaesthesia for adenotonsillectomy.

Two objectives of anaesthesia for T\&A, control and protection of the airway, are not invariably achieved with tracheal intubation. Small tracheal tubes can be kinked and partially obstructed and protection of the lower airway by uncuffed tracheal tubes against aspiration of blood is not assured. In a recent study comparing uncuffed tracheal tubes and the LMA for T\&A, ${ }^{12}$ fibreoptic laryngoscopy demonstrated that with tracheal intubation, aspiration of blood occurred in $54 \%$ of children and $15 \%$ of adults, whereas the LMA protected the lower airway. We observed no laryngeal contamination, and no blood on the laryngeal surface of the LMA in any patient.

Management of tracheal extubation in children is the subject of continuing controversy. Two recent studies reached different conclusions. In one of these, awake tracheal extubation after either isoflurane or halothane anaesthesia was followed by more episodes of oxyhae- 
moglobin desaturation than after tracheal extubation while anaesthetized. ${ }^{13}$ In the other, the incidence of airway-related complications such as laryngospasm, croup, sore throat, excessive coughing and arrhythmias was no different between those extubated while anaesthetized or awake. ${ }^{19}$

Awake extubation, after inserting a bite block to prevent the tube from being occluded during return of reflex activity, has been reported using the LMA in children. ${ }^{14}$ In our study there was a lower incidence of stridor after removing the LMA than after tracheal extubation $(P<$ 0.05). Removal of the LMA while the patient was anaesthetized exposed a potential hazard because, in two patients, insertion of an oropharyngeal airway to relieve upper airway obstruction after removing the LMA was followed by severe laryngospasm.

Opening the B-D gag and adenotonsillectomy are powerful noxious stimuli. The associated high incidence of reflex responses, adverse events, and the need for assisted ventilation suggest that the depth of anaesthesia was often inadequate. After the bolus injection of propofol, rapid redistribution and biodegradation may have led to return of protective reflexes before adequately deep inhalational anaesthesia was established. Responses in the LMA group to opening the B-D gag during this period of vulnerability included ten episodes of airway obstruction, five with oxyhaemoglobin desaturation. In three cases early in the study, uncertainty as to the cause led to immediate conversion to tracheal intubation. With further experience, an increased induction dose of propofol, and deeper inhalational anaesthesia, the incidence of adverse events was diminished. With fibreoptic laryngoscopic evidence of mechanical obstruction in only one case we concluded that, in our study, the likeliest cause of airway obstruction on opening the B-D gag with the LMA was inadequate anaesthesia with reflex laryngeal closure.

Our experience demonstrated that control of airway reflexes is essential for successful use of the laryngeal mask airway for adenotonsillectomy. The LMA did not limit surgical access, and we found no evidence of aspiration of blood into the lower respiratory tract. The need for assisted ventilation was reduced and haemodynamic responses were diminished compared with tracheal intubation. The incidence of post-extubation complications was reduced but not eliminated by using the less invasive laryngeal mask airway.

\section{Acknowledgements}

The authors wish to thank the nursing staff of the Children's Ambulatory Care Unit, the OR and PACU of St. Joseph's Hospital, L. Stitt, MSc for statistical consultation and Drs. Ann K. White, Kam Yue and T. Wayne Matthews, otolaryngologists, for their collaboration.

\section{References}

1 Doughty $A$. Anaesthesia for adenotonsillectomy: a critical approach. Br J Anaesth 1957; 29: 407-14.

2 McAlpine DF, Bowering $M W$. Anaesthesia for tonsillectomy and adenoidectomy in children. Can Anaesth Soc $J$ 1958; 5: 61-71.

3 Ribiero OV. Anesthesia for tonsillectomy and adenoidectomy in children: observations on 10,000 cases. Anesth Analg 1960; 39: 189-96.

4 Naunton RF. Tonsillectomy and adenoidectomy: current technique. Surg Clin North Am 1961; 41: 213-9.

5 Black $A E$, Mackersie $A M$. Accidental bronchial intubation with RAE tubes. Anaesthesia 1991; 46: 42-3.

6 Sen $A K$, Gupta B. Herniation of RAE tube through split Boyle Davis gag (Letter). Anaesth Intensive Care 1990; 18 : 577-8.

7 Brain AIJ. The laryngeal mask airway - a new concept in airway management. Br J Anaesth 1983; 55: 801-5.

8 Brain AIJ, Mc Ghee TD, McAteer EJ, Thomas A, AbuSaad MAW, Bushman JA. The laryngeal mask airway: development and preliminary trials of a new type of airway. Anaesthesia 1985; 40: 356-61.

9 Brodrick PM, Webster NR, Nunn JF. The laryngeal mask airway: a study of 100 patients during spontaneous breathing. Anaesthesia 1989; 44: 238-41.

10. Maltby JR, Loken RG, Watson NC. The laryngeal mask airway: clinical appraisal in 250 patients. Can J Anaesth 1990; 37: 509-13.

11 Alexander $C A$. A modified Intavent laryngeal mask for ENT and dental anaesthesia (Letter). Anaesthesia 1990; 45: 892-3.

12 Williams PJ, Bailey PM. Comparison of the reinforced laryngeal mask airway and tracheal intubation for adenotonsillectomy. Br J Anaesth 1993; 70: 30-3.

13 Pounder DR, Blackstock D, Steward DJ. Tracheal extubation in children: halothane versus isoflurane, anaesthetized versus awake. Anesthesiology 1991; 74: 653-5.

14 Mason DG, Bingham RM. The laryngeal mask airway in children. Anaesthesia 1990; 45: 760-3.

15 Dain SL, Smith BD. Webster AC. A laptop computer based intra-operative physiological data acquisition system. Can J Anaesth 1992; 39: A31.

16 Motoyama EK, Cook $C D$. Respiratory physiology. In: Smith RM (Ed.). Anesthesia for Infants and Children. 4th ed. St. Louis: CV Mosby 1980; 38-86.

17 Koka BV, Jeon IS, Andre JM, MacKay I, Smith RM. Postintubation croup in children. Anesth Analg 1977; 56: 501-5.

18 Olsson GI, Hallen B. Laryngospasm during anaesthesia: a computer-aided incidence study in 136,929 patients. Acta Anaesthesiol Scand 1984; 28: 567-75.

19 Patel RI, Hannallah RS, Norden J, Casey WF, Verghese $S T$. Emergence airway complications in children: a comparison of tracheal extubation in awake and deeply anesthetized patients. Anesth Analg 1991; 73: 266-70. 